\title{
Hosting an International Conference on Women and Shelter: Pedagogic and Logistical Insights
}

\author{
Hemalata C. Dandekar and Sujata Shetty
}

Conferences may, and sometimes do, play several important pedagogical roles for both faculty and students. Unlike teaching courses, organizing a conference is not an experience that is repeated over and over again. As a result, there is not much opportunity to learn individually from mistakes, and collectively the learning curve is severely truncated. New entrants into the conference game are forced to reinvent the wheel. This paper attempts to extract some elements of our experience- - both substantive inquiry and logistical arrangements-which may be useful to other academics considering this ubiquitous but under-studied pedagogical form. We address primarily the process issues involved in designing the intellectual content of the conference and the lessons that were learned, and we refer to the substantive issues that surfaced in the experience of hosting the conference.

This international conference was extremely valuable to us intellectually, for the range of ideas and viewpoints that were ultimately presented broadened our own perceptions of the topic. In organizing it, we also learned much about university and institutional administration. Hosted at the University of Michigan, 7-9 May 1992, this was truly a development project for us in personal terms. In keeping with Hirschman's (1967) predictions about very large infrastructure projects for development in the Third World, ${ }^{1}$ had we known at the start just how much overall effort it would take to bring this to a successful conclusion, we probably would not have initiated this project at all. But looking back on the process, and beginning to understand the obvious as well as the more subtle achievements, it is clear to us that this was an important and useful undertaking. The process of participating in the conference and its design and execution itself helped many individuals to clarify or confirm their own research or practice focus. Graduate students, particularly doctoral students, drew energy and direction from both the process and the outcomes.

The conference proceedings, titled Shelter, Women and Development: First and Third World Perspectives, (Dandekar 1993a) have been published in book form. ${ }^{2}$ We believe that the more than 50 authors featured in this book have, as a group, made a useful contribution to advancing the thinking on the special role that housing, or shelter as it is commonly referred to in the Third World, plays in women's development. This book would not have taken its present shape without the conference, which became a venue for presentations on and discussions of this topic. Following the conference, Dandekar spent almost a year and a half organizing, editing, and bringing submitted papers to publication. She is presently at work on similarly organizing for publication the visual and graphic materials shown in an exhibit which ran concurrent with the conference. ${ }^{3}$

This paper is written from the two viewpoints that contributed to the success of the endeavor-Dandekar's perspective of the academic professor, teacher, and

\author{
AbSTRACT \\ The experience of hosting an international \\ conference at the University of Michigan on \\ the topic of shelter, women, and development \\ provided the authors of this paper with two \\ kinds of insights. First, there was useful \\ substantive information which broadened our \\ delineation of the subject area addressed. \\ Second, we developed a heightened awareness \\ of university and institutional administration \\ and the logistical issues that must be attended \\ to if faculty/student initiatives are to succeed. \\ This paper extracts some elements of this \\ experience in the areas of substantive inquiry, \\ logistical arrangements, and implications for \\ pedagogy, which may be useful to other \\ academics considering similar activities. In \\ this paper we favor the process issues involved \\ in designing the intellectual content of the \\ conference and its output, believing them to \\ be applicable to other initiatives which seek to \\ weave together pedagogy, research, and \\ action, depending on the culture and the \\ mandate of the host institution.
}


researcher and Shetty's perspective of the graduate students who participated in organizing the conference and made it a part of their overall academic effort. Participants in both of these roles benefited. We describe these benefits, as well as some of the liabilities. An understanding of the experience for students in the core organizing group, was obtained by Shetty through informal conversations and discussions while preparing for the conference. Shetry then spoke individually with several of the students soon after the conference and again about a year later. This paper provides a brief introduction to the context in which the conference was conceived, followed by its substantive evolution, the conference event, and some concluding reflections.

\section{- Conference OWnership and Resources}

At the onset we need to make clear that the women and shelter conference was a purely grass-roots initiative of faculty and students. It did not arise out of an administrative or institutional mandate within the university. This important point had great implications for some of the logistical and pragmatic constraints we experienced. Many of the bottlenecks might have been avoided had this effort been initiated by a high-level administrator with control over allocating staff support and financial flexibility. ${ }^{4}$ On the other hand, that this was a faculty-student initiative was central in eliciting a high level of group commitment and input of time and energy. This was critical in making the conference happen, despite constraints.

Although thematically and substantively the efforts spearheaded by faculty and students can often be stimulating and cutting edge, the administration of the university and its priorities can make their actualization quite difficult. If faculty are able to obtain outside funds to pay for staff support, then some of the difficulties can be alleviated. However, by the time outside sponsors accept the ideas as worth backing, the ideas are often not cutting edge and exploratory, but already safe (i.e., "good currency" in Schön's [1971] terms). Sometimes university conferences can serve as useful precursors to this stage, when the intellectual effort is in defining, conceptualizing, and formularing the parameters of an intellectual area deserving attention. University administrators (e.g., deans, provosts, and vice-presidents for research) charged with fostering such research and scholarly activity, play a key role in determining where and how scarce discretionary resources are to be used to achieve these breakthroughs. Unit administrators such as college deans are needed to endorse the substantive elements and make local unit commitments; central university administrators must recognize the worth of the endeavor and back this up with central resources. This can be difficult in a large university, as the expertise represented in faculty research and activities covers a broad intellectual terrain.

Academic initiatives from fields like planning and architecture are at a disadvantage in the more "mainstream" assays of intellectual worth at central administrative levels because, besides theoretical concerns, their initiatives often include matters of practice and policy. Despite the rhetoric about community service at a public research university such as University of Michigan, there is considerable uneasiness and vagueness about what is legitimate for faculty to undertake in the policy or service area. ${ }^{5}$ In fields such as architecture and urban planning, more important than a good idea for a research initiative possibly involving a conference, is obtaining administrative sponsorship and ownership of the activity, both internal and external to the university. A clear understanding of this fact and knowing how to leverage and garner administrative support may be the critical ingredient for success.

Our initiative started with a successful proposal for $\$ 5,000$ of seed money from the University Council on International Academic Affairs. Over the next few months we were able to use this initial grant as leverage to get smaller sums of money from our own unit, the College of Architecture and Urban Planning (CAUP), and from across the campus. Among our sponsors were the Graduate School, the office of the Vice President for Research, the Office for Minority Affairs, and the Women's Studies Program. These units responded both to the issues and geographical areas to be discussed and to the interdisciplinary nature of the conference. The essential point is that the topic was of interest to people in many disciplines.

The original proposal was for an invited lecture series by international experts working in different countries and with different aspects of shelter, women, and development. The approximately $\$ 12,000$ in university funds and additional in-kind support from CAUP enabled us to issue information about registration. The robust response to our call for papers began to indicate that a meeting truly international in participation and content was shaping up. We made sure that this was understood by our dean and other external sources of support. As a result, we were able to get some $\$ 25,000$ in support from two U.N. agencies: the United Nations Centre for Human Settlements (UNCHS) and the United Nations Development Fund for Women

(UNIFEM). In addition to providing a boost to our morale and visibility to the conference, these grants increased our credibility and legitimacy within the college and allowed us to support travel expenses for several Third World participants. Given the limited amount of internal money available for endeavors such as this, it was crucial to get outside support. Our external resources primarily funded the travel and room and board for participants from abroad; internal resources went toward partial support for participants from the U.S. and for hosting and managing the conference. All the participants who were given formal support were independent practitioners or activists who would otherwise not have been able to attend. Domestic funding for a conference 
such as ours seemed to be difficult to obtain because sponsors were looking for intervention programs and activism and because in women's issues, housing was not high on the list of priorities of any major domestic foundation.

The process of leveraging early commitments of money into commitments from other agencies was enlightening. Dandekar's experience as a central administrator was invaluable in knowing when to hold firm, when to withdraw, and when to acquiesce. If we had not publicized and generated interest in the conference before all the needed funds were in place, we would not have obtained the support. For example, UNCHS money was obtained not only because of its interest in the topic of the conference, but also because of the magnitude of the response to our call for papers. In turn, its investment was instrumental in our convincing UNIFEM to fund additional participants. Getting funding for an event like this is a dilemma. Agencies look at the proposal to gauge the content and quality of the conference before making funding commitments. They look at other sponsors to get a sense of how legitimate the conference and its aims are. But at the time one is seeking funds, most of what the agencies are looking for is nebulous because 1) the central themes and directions of the conference are still emerging; 2) a majority of the participants, particularly activists and practitioners, are unable to make commitments if travel support is not forthcoming; and 3) participants are deciding whether the event will be worth their time.

\section{- Evolution of the Conference}

The substantive focus of the conference was established in our first conversations in January 1991. We remarked that very little work appeared to concentrate on women's shelter needs as separate from a family's needs for housing, and even less that linked such thinking with women's potential for development. Between us we could name three or four books significant in the area. As an architect/planner who sometimes works specifically on issues of women's development, Dandekar had been interested in this connection for some time. She was exploring some aspects of this topic in pilot research on sites and services projects in $\mathrm{Ma}$ dras and Bombay (Dandekar 1993b) and had referred to it in her book on rural women from a village in Maharashtra, India (Dandekar 1986). We wondered who was presently doing work on this topic, and whether we could we bring them to Michigan to obtain an update on the state of the art. Our preliminary review of the literature revealed a small, select number of offerings in First or Third World contexts; very few juxtaposed the two worlds or offered any theoretical or conceptual framework for understanding the links between shelter, women, and development. ${ }^{6}$ It also appeared that professionals in practice (e.g., architects, planners, social workers, lawyers) who were dealing with various aspects of the topic were talking within their own professions.
Clearly we could not address this dearth in conversation about the topic directly in our own work, but we wondered if, by way of a conference, we could stimulate what we perceived to be a much needed conversation between activists, policy makers, professionals, and academics. We discussed this idea with students and faculty around the University of Michigan campus, and there appeared to be a great deal of interest in such an event. From our informal talks with interested people both on and off campus, it was obvious that different disciplines viewed the issues from their own perspective. The seed money we obtained in the university had been based on a proposal for a small, invited lecture series by experts. In light of the considerable interest within the university, we expanded, with some trepidation, our original plans with a call for papers to probe who was out there doing new and interesting work on the topic. Meetings of experts, as we had originally envisioned, are easier to organize logistically and important to do if the field is well defined. But in this case, given the particular slant we wanted to take, we found few publications and preceding conferences, and none recently convened in North America. In addition, for the topic to be explored in all its dimensions, input was needed, not from academic research alone, but equally through representation of the work of practitioners and activists in the field. In our case, on intellectual grounds it proved to be a successful strategy to go with a broader call for expressions of interest.

Looking for a broad range of participation resulted in a much richer mix and interaction, but international representation magnified the logistical burdens and administrative aggravations. The word spread. We got responses from Saudi Arabia, South Africa, Costa Rica, Nigeria, Egypt, Sweden, UK, Malaysia, Mexico, India, Bangladesh, and, of course, several regions of the US and Canada. Preponderantly, the responses were from women, although there were architectural and planning firms headed by men that sent projects for the exhibit. The mix of First and Third World types, the topics covered, and the fact that academics, activists, and practitioners were represented resulted in an unevenness in writing styles of the papers finally submitted for the proceedings, but provided a richness of viewpoints and discussions of new facets of the problem and its solutions. In keeping with the spirit of the conference, Dandekar made a commitment to be inclusive and to have all the different voices heard in the book.

\section{Conference Goals}

In defining the substantive parameters of the issues to be addressed, as students and faculty primarily involved in the professions of architecture and urban planning, we took shelter as the primary and overarching element in the questions to be addressed. Women's relationship to shelter and its implications for their development were the next order of priority in framing our inquiry. Thus the needed 
link between the thinking about women as a special group with specific needs for and relationship to shelter was articulated. The objectives of the conference were as follows.

1. Establish that access to shelter is an important component of women's ability to achieve development; that housing issues have significant implications for the economic, legal, and social status of women around the world; and that independent access to housing might become particularly important for women in societies where development is carrying societies from the traditional to the modern.

\section{Explore whether there is something to be} gained from taking a cross-cultural, crossnational, cross-class look at the issues. The underlying expectation was that the gender of a person seeking shelter makes for common attributes transcending the boundaries of culture, nation, and class. It was anticipated that these commonalties would surface, as would differences, when one compares the issue in First and Third World contexts.

3. Establish a connection between the issue of women and their shelter with the larger discourse on women and their development; bring to focus the idea that a gendered approach to provision of shelter can yield development for women.

\section{Identify opportunities for redesigning policy to enhance women's access to shelter and thus facilitate their development. In short, the idea was to talk both about the problems and about creative solutions.}

\section{Thematic Focus}

Through collective deliberation by the organizing committee of students and faculty, we identified seven themes that seemed important in discussing women's access to housing and its implications for women's development. These were set forth in the call for papers. From the abstracts that we received we found a substantive interest in two more themes, which were added to the list. These nine themes, eventually addressed in some 55 presentations at the conference, were as follows.

\section{Shelter Policy: Implications for Women's Development}

The Structure of Legal Interventions

Shelter and Women in Crisis

Women's Participation in the Production of Shelter

\author{
Shelter and Income Opportunities \\ Women and Shelter-Related Services and \\ Infrastructure \\ Nontraditional Living Arrangements: Beyond \\ the Nuclear Family \\ Design and Creation of Shelter for Women \\ Shelter Options for Elderly Women
}

The idea of allowing the papers submitted to guide us toward what people were talking about in the field, and therefore allowing the submissions to give form to the conference, was both interesting and unsettling. One student thought this process somewhat arbitrary and wondered if this is how most conferences worked or if there were other ways to do this. Most students noted that we added panels on design and housing for elderly women after we received several abstracts that dealt with these issues, even though they were not mentioned as topics in the call for papers. To these students the flexibility of the process was an advantage. Some planning students saw it as a reflection of their idea of the planning process-open, flexible, and able to incorporate useful feedback.

We consciously defined the subject matter narrowly in its relationship to the built form. Environmental considerations were limited to shelter-related physical infrastructure. Given that large-scale environmental issues were, and continue to be, addressed in other very visible global venues, this delineation made sense to us. Even so, we found that a very large terrain was encompassed in our delineation of themes. The abstracts we received, especially those that developed gender-based case studies of particular shelter provision efforts, often addressed issues that illustrated several of the nine themes simultaneously. Papers were placed within particular themes on the basis of the original abstracts, sometimes after discussion with the authors.

\section{Conference Planning}

The major determinant of attendees at the conference and consequently of the conference's design, was the amount and timing of funding. As noted earlier, putting the funding together was extremely time consuming. It is especially crucial to have funding in hand early if one is getting participants from other countries, particularly the Third World. Two participants who would have contributed greatly to the conference were unable to attend. One, from the Women's Construction Collective, Jamaica, received confirmation of the funding we ultimately obtained for her too late to complete the rest of her travel paperwork. The other, an academic and practitioner from Nigeria, was denied a visa by the State Department because she was single and the government was fearful she would stay in the US! At a minimum, about three to four months lead time for assured funding seems essential to get Third World participants. It would also have given us more time to spend 
on preparing for the event itself. We found, too, that it was hard to get practitioners from World Bank-type institutions who had interesting perspectives on policy. Most of them travel constantly and were unable to make firm timecommitments.

The registration fee was kept as low as possible. We made an effort to keep people together by scheduling meals together and, where possible, having them stay together, because it was clear from the beginning that the participants had a common agenda that went beyond their presentations at the conference. We converted one of the architecture studios into a cafe, where under colorful umbrellas in a large, bright, airy room we met for meals and coffee breaks. Participants thus had the cafe and the exhibit gallery to use as informal meeting places. Facilitating these informal meetings, we felt, was an essential part of the conference so that connections could be made and conversations sparked by the presentations could be continued. For us, this was an important part of the outcomes we were hoping for.

The limited resources available within the college forced us to use the services of the university's conference division. This, as it turns out, created more problems than it solved. With a longer chain of command, we had much less control and the organization process became more complicated. Also, perhaps because of the division's lack of experience with a large number of attendees from abroad, farming out the logistics was, ultimately, a bad idea. One or two fulltime staff within the college could have taken over the responsibility and made the process much more efficient. But the college could not provide the staff. In the final analysis, it seems to us that keeping the entire organizing effort within the college would have been not just more efficient, but more cost effective as well. It took more than one and a half years after the conference for accounts to be closed by the conference division and some funds were lost because of poor follow-up and execution.

\section{Core Concepts}

In the period between acceptance of abstracts by January 1992 and the conference itself in May 1992, to further define the theoretical and substantive boundaries for operational purposes, each theme was reviewed and amplified by graduate-student moderators in collaboration with a faculty moderator who assumed overall responsibility for the theme. Dandekar worked with a core group of 12 students, who divided responsibility between themselves for the 9 themes and for some of the logistics. Student moderators were charged with defining the boundaries of the theme and writing an overview piece that would set the context for the ideas explored and weave together the papers presented in that theme. The cooperative nature of the undertaking was reflected not only in logistical matters but in the faculty/student partnerships that were developed in moderating themes. Each theme had a faculty moderator to help the student moderator(s) conceptualize the themes. Faculty moderators were from the departments of architecture, urban planning, art, social work, anthropology, and women's studies. Students were from the departments of architecture, urban planning, social work, natural resources, and law. Faculty involvement with the conference varied in intensity across themes, but in most cases was critical in shaping the substantive, thematic overviews. The logistical, organizational burden of making the conference work was borne primarily by Dandekar and core student moderators.

Student moderators expanded on the thematic boundaries and communicated these to their panelists. These thematic outlines were provided in the conference program to help situate individual papers in a larger context for panelists and conference attendees. Following the conference and reflecting on the discussions that occurred during it, overview papers further delineating the thematic areas and framing the issues were written by several of the student moderators. These were included in the proceedings as the lead paper in each thematic section. Thus students' involvement as moderators culminated in publications in the final book and provided them with first-hand experience of the responsibility of shaping an intellectual core, of dealing with practical logistical issues (i.e., making the process work), and of dealing with the intellectual egos and concerns.

\section{Pedagogic Infrastructure}

The "Housing and Infrastructure Seminar" offered by Dandekar each winter term became the forum for discussing the issues that the conference addressed. The theme for the semester preceding the conference was "Shelter, Women and Development: First and Third World Perspectives." All the students in the core group and others comprised the class, although not all students took it for credit. The thematic outlines and the overview papers written by the student moderators for each theme were developed in this class. Each week after the first, the class concentrated on one theme and the student moderator/s for that theme presented their work and a brief summary of the papers that were to be included in their panels. Students said that they found the discussions in class stimulating and the feedback very useful. As one student put it, the dialogue here and later at the conference was very affirming.

Planning students in particular felt that, unlike the other classes offered, this seminar had a tangible focus and an end to work toward. The class worked together to create an event which in itself was seen as very satisfying. However, there was a sense among some students that the boundaries between the substance of the conference and organizing the conference could get blurred. For example, it was possible to move from discussing the content of a paper to a broader discussion on the form of the conference, and one had to be vigilant about such diversions.

There was a great deal of diversity in the class. There 
were undergraduate, master's, and doctoral students from different disciplines; hence there were differences in their familiarity with the issues the seminar addressed. Some of the students felt that a set of assigned readings would have given the class more common ground to work from. The publication of the conference proceedings (Dandekar 1993a) will make this possible in the furure. However, at that time student theme-moderators were doing the preliminary literature searches needed to surface the pieces salient and central to their themes and fleshing out the parameters of the themes.

Many of the student moderators said that their participation in several aspects of the conference and the relative freedom within their theme was very empowering and gave them a sense of belonging and of ownership. Once the participants were broadly divided into the nine themes, student moderators worked with the participants in their theme, helping them to shape their papers and giving them some idea of the other papers in their panel. Some students looked for funding for participants in their theme; others solicited papers from people whose point of view they thought was important to bring to the conference.

It became apparent very early on that the themes of the conference had a strong visual component. Several responses to the call for papers and exhibits included drawings and photographs of schemes and/or built work. We also had some responses that dealt with shelter and women's needs for shelter not only in construction, space, or form, but also the sense of shelter, of inner space. From this point on, the accompanying art and photo exhibit that we mentioned in the call for papers (wondering if we would get any responses at all) took on a whole new meaning. The exhibit was no longer just a way for design participants to show their drawings or for activists who brought in display boards to show their efforts. It assumed a separate identity and gave a separate and independent physical form and imagery to the conversation at the conference presentations. It brought out the poetic and the spiritual, the visual and the tangible.

Two architecture faculty members, Professors Melissa Harris and Elizabeth Williams, took the lead by cochairing the exhibit. ${ }^{7}$ With a group of students, they used the exhibition as an opportunity to mix pedagogy with practice. As part of an experimental course on exhibition design, students designed and built a showcase for the exhibitors' work. Exhibited were short video films, architectural drawings of built and planned projects, photographs, paintings, sculpture, and poetry. While some exhibits were grounded in the physical (e.g., plans and elevations for a women's shelter), others were artistic explorations of the inner psychological values of shelter. An important part of the exhibition was the book display, where we gathered together various books relevant to aspects of the topic.

The conference had greater intellectual value for students because it was not a one-time event, but had two classes held in conjunction with it. While the seminar class used their time to develop the ideas and issues that comprised each theme and the links between them, the architecture class worked on the exhibit in an experimental course where a conscious attempt was made to reflect the spirit and content of the conference, both in the process of designing the exhibition and in the design of the objects that were built to display work that was submitted. The students who worked most closely on the conference and exhibit thus had a semester of academic work that led to the event itself.

The flip side of this is that the conference and exhibit were made possible by students and by the infrastructure that a university provides. Students, guided by faculty, created the conceptual framework within which the papers for each theme were presented. This helped bring together an enormous range of ideas and approaches in a way that made them easy to discuss and analyze. Students, again guided by faculty, also designed and built the structure for the award-winning exhibit at minimal cost using internal funding and the facilities available at a large university, such as a professional-quality art gallery and woodwork shop. Mounting such an exhibition privately would have been prohibitively expensive. We believe that the discourse at the conference gained as much from the fact that it was held at a university and from strong student participation as students gained from the discourse provoked by the conference.

\section{Conference Logistics}

The conference itself went off without a hitch, even though we were forewarned that there was a possibility that First World/Third World tensions might surface. Looking back, we avoided this possibly because

there was a very clear focus on a tangible issue, shelter for women;

the mix of participants meant that we were low on rhetoric; and

several professionals (architects, planners, lawyers, policy makers) were there, interested in implementation and action, and looking for connections with activists and vice versa.

Time constraints dictated parallel sessions, but we organized a few plenary sessions for panels that we thought addressed issues of urgent and/or universal interest. Some of the questions that came up when discussing what was learned in running the three-day conference had to do with students' lack of familiarity and lack of experience with this type of forum. There was dissatisfaction that panels ran concurrently and that strict scheduling often did not leave enough time for discussion at the end of each set of presentations. The main question was whether we had a predeter- 
mined picture of how a conference is run and then made the participants and their presentations fit that picture. In other words, did we give the form more importance than it deserved?

Some students were disappointed that the conference had fewer participants than originally anticipated, although the conference was the biggest the college had ever hosted. Attendance was heavy to the closing minutes and beyond, when large groups of attendees went to local restaurants and continued their conversations. In analyzing why the conference was not bigger, students felt it was for reasons of timing, location, and publicity. For practical reasons, including availability of space in the college, the conference had to be held soon after the term ended, by which time many students had left. The panels had enough variety and drawing power to interest undergraduates and other members of the university community, and we would have had much wider participation (particularly since it was an open university event) had the conference been held during the term. Second, the conference was held at the College of Architecture and Urban Planning at the university's north campus, which is somewhat removed from the central campus where the majority of students attend classes as well as live. Students felt that a central campus venue might have attracted more drop-in participants. However, finding space on central campus for a three-day event in the middle of a term would have required much greater administrative clout than we could have mustered. Third, students mentioned that we had fewer local participants, particularly from the Detroit area, than hoped for and felt that a more organized and formal publicity campaign might have drawn more participants.

Although we made a concerted attempt to have participants from the local Detroit area, we needed more person power toward the end and more secure funding at the start to enable us to finalize the participation of local activists. However, we were able to get local activists in addition to several attendees in the panels on crisis, law, and the elderly. Much of the success depended on how proactive and motivated student moderators were in pursuing and finalizing arrangements with local participants. While we could get some of these extremely busy activists and practitioners to participate, it was very difficult to bring in the university's central administration. At the same time that we had a genuine international conference on a shoestring budget at one end of campus, many administrators were at a high-profile conference at the other end, where a group of experts and educators talked about the internationalization of education. Although the dean of our college graced the important moments of the conference, there were perhaps two reasons for the apparent lack of interest on the part of the central administration. First, women administrators at the university are few and far between. Second, women's issues and conferences dealing with such issues are very low on male administrators' list of priorities. This became clear as we were not able to find any executive officer or associate from the offices of the president, provost, vice president for research, or graduate school dean to attend the major conference banquet: it was too short notice. But on equally short notice our state senator, Lana Pollack, a woman, not only graciously attended, but delivered eloquent comments that are the epilogue to the book developed from the conference.

\section{Analysis of Process}

The work of hosting the conference and publishing the book has involved enormous amounts of energy on the part of various people throughout the process. When we were in the throes of making the conference happen, administrators within our unit criticized that we had not "planned well" and should have better anticipated what would be needed and when. Although we acknowledge that some of our effort might have been deployed more efficiently had we had a more detailed understanding of what it would take to attain our goals, we believe that, true to Hirschman's postulates about development projects, some of these goals and needs become apparent only when one is in the middle of a development venture. Hirschman $(1967,12-13,70)$ postulates that the organization or system must learn to respond constructively to these emerging needs as they are encountered, and this is how creativity is unleashed and true learning/development occurs. We believe that the outcome of our collecrive effort on this conference was creative and perhaps pathfinding precisely because we turned resources in the directions that intellectual understandings revealed during process. This Lindblomesque incrementalism (Lindblom 1965) and our practice of adapting old agendas and taking on new foci were important in the intellectual endeavor. By and large, we believe that the time and energy it ultimately took to make this event happen was in fact appropriate and requisite. We fault ourselves for not clearly understanding the overall institutional parameters at the start and for being naive about the administrative ownership issues that we referred to earlier. We were unable to garner true administrative commitment within our unit since this was not an administrative initiative. Knowing the consequences of this and having some insight into what that would imply from a staffing point of view would have been helpful, at least psychologically.

\section{Substantive Insights and Products}

The conference was designed to explore whether there were legitimate reasons to look at the linkage between women and shelter in the first place and whether there was some virtue to taking a cross-national, cross-worlds perspective. The conference and book definitively established that there was. The discourse at the conference and contributions to the book revealed there were several reasons to look 
at the issues cross-nationally; that internationally, women face problems of attaining shelter that are directly related to their gender; and that housing is of greater significance in the development of women than of men. These insights are elaborated on in the over 50 contributions published in Shelter, Women and Development: First and Third World Perspectives (Dandekar 1993a). Policy implications that arose out of this collective vision are discussed in a forthcoming article (Dandekar in press).

The book is the most tangible outcome of the conference. Producing it was important because too many conferences end with the event and because we hoped it would make a broader impact on how this topic is framed and addressed in future discourse. This has begun to happen. In June 1994, an international seminar on gender, urbanization, and environment was held in Nairobi, Kenya. The book was in circulation among organizers of the Nairobi seminar, and some of the themes that came out of the shelter and women conference formed the basis for discussion. Dandekar was actively involved in shaping some of the substantive content of the Nairobi conference. The work done at Nairobi will continue at a larger, global conference to be held in Beijing in 1995. The conference and book have thus been a way for activist, practitioner, and academic concerns to be represented in a global policy forum, and to contribute to shaping policy. The conference and the book have served as valuable teaching/service tools, and also as leverage for this next round of conference activity.

There have also been two less tangible but extremely important outcomes of the conference effort. First is the connections that the participants made with each other. The four participants from India, for example, were working on different aspects of shelter, women, and development, but had either not met before or were only vaguely aware of the others' activities. Nor had many First and Third World participants working on the same topics been exposed to each other's work before. By putting First and Third World participants and combinations of academics, practitioners, and activists on panels together, the dialogue was started. We hope it will continue. We have had indications that this has happened. A presenter from the UK and one from the US met in Mexico, the site of their individual projects, and pooled information. According to comments that participants have made to us, the fact that there was so much interest in the topic and that such a large group of interested individuals participated and attended was apparently very empowering to some of the women who had been working in isolation.

Second, for several of the students who worked on the conference it was an important intellectual passage. In the seminar during the semester preceding the conference, students presented and critiqued the substantive issues that came up in each theme. Writing the overview piece for the theme they were in charge of forced them to articulate and give formal shape to these ideas. This meant distilling First and Third World perspectives as well as discussing different approaches-academic, practitioner, or activist-within the framework of one theme.

One important aspect of the conference which manifested itself in First World- and Third World-based work was the intensely personal nature of the presentations. Whether academic, practitioner, policy maker, or activist, the speakers usually exhibited their empathy and sense of solidarity with the women they encountered in their work. Speakers seemed to believe deeply in the importance of talking about and mobilizing opinion and action on the issues they addressed. In fact, one student felt that if we had sensed this earlier we could have created one or more roundtables where participants spoke of the personal meaning of their work.

\section{- REFLECTIONS}

There are several specific insights that have emerged from our experience that might be helpful to others considering similar initiatives. We present them here in two categories, logistical and pedagogical.

\section{Logistical Insights}

The overall opinion was that we were constrained by lack of time and adequate experience to do all the things we wanted to do. Looking back, one would have to emphasize the importance of institutional support early in the process. The process of organizing the conference was much more labor intensive than we initially anticipated. Doubling the lead time would have been a more appropriate estimate of the amount of work involved. It was clear, also, that the conference topic was not on the list of priorities of major funding agencies, so there was a great sense of anxiety in the earlier stages when the funding was not yet in place but the emotional commitment to the conference had been made. Yet there was a shared sense of purpose and of risk-taking and an intuitive feeling among the students that it was important to go forward-a belief that if we stuck with the idea of the conference long enough and worked at it, it would happen. Looking back on the event, one student moderator who has moved to another university recently made the comment that the conference and the book have had a charmed existence, succeeding despite very poor odds and substantial obstacles.

In retrospect, the process described here may not have been the shortest or most efficient way, administratively, to get from the point when the conference was first conceived to the time it actually occurred. We were accused of not being linear enough and of not having anticipated well enough what to expect in a process such as this. Yet it seems that it was precisely because we took a meandering path that we got as much, intellectually, as we did from the confer- 
ence. It is not a path we would recommend for all. At every stage of the process, there was the real possibility that the conference would not go through. Limited institutional support for a project such as this and the fact that it is hard to get other faculty to commit any real time, means that the conference chair bears virtually all the responsibility.

Tenacity and a tough skin are needed, as well as confidence in the intellectual merits of the effort.

Internal support is important to the success of such a venture, particularly if it is tackling a new topic that is not yet in good currency. So why might unit heads or deans think about promoting such a venture? Perhaps precisely because university administrations talk about an international focus and interdisciplinary efforts on the part of faculty and departments, it behooves deans to support activities that embody these values. Particularly in areas where no one is yet taking responsibility or ownership, there are opportunities to make an early breakthrough. It is important in this context for unit heads to realize the scope of the commitment once it is made, even if the organizers themselves may not fully recognize it. University administrations might also be interested in public service credit for such a conference. Most state institutions are pressed to deliver more to their communities, and a strong, early commitment combined with local and regional involvement could generate additional mileage. In retrospect, given the mandate on public institutions to provide service, had we started earlier we might have been able to co-opt the administration into ownership of the project. But we question whether we could have stayed as focused on the idea sets we identified as important.

With regard to conference sessions themselves, we feel that we should have had more time for discussion following presentations as well as separate roundtable sessions where issues that cut across the themes of the conference could be discussed. Some students were pleased with the selfcontained nature of the panels and their ability to stand on their own, while others felt that the panels were too tightly organized around predetermined themes and did not talk to each other. Looking back, we wonder if we could have mixed the presentations so that commonalties were more easily identifiable. As in most conferences, we had to organize panels on the basis of abstracts submitted. As is usual, the actual papers presented often diverged to a greater or lesser extent from these original submissions. Certainly, given the base of understanding we developed and the collection of papers available to us in the book, if we designed a follow-up effort we would be able to structure the panels in a more integrative way.

Some students felt that we should have planned to create more opportunities for students to connect with activists and practitioners, particularly to explore the connections between the academic work that is possible in a university setting and the needs of the outside world. As most partici- pants were only in town for the three days of the conference and there was little other free time, we made a conscious attempt to organize meals together so that participants would have time to meet outside the sessions. Although it was not possible on this occasion, students felt that if all the participants had stayed at the conference venue there would have been greater opportunity for interaction. The organizers, however, were unable to control where participants not receiving support stayed. For participants we did support, we planned room allocations to maximize discussion. We were told that many late-night conversations resulted.

The concurrent sessions at the conference meant that most participants were unable to get the kind of overview of the entire conference that Dandekar got from editing the papers that were submitted. The book thus functions as an integrating tool, facilitating an intellectual starting point for a future gathering.

Who, then, should undertake such a venture and why? As an academic pursuit, organizing a conference such as this is a rewarding way of pushing one's thinking forward, if one has the time to do all the groundwork and follow-up work that is necessary. The time and effort required would be an important factor in determining when in one's career is the best time to make such an effort. It is perhaps not particularly suited to an academic at the start of his/her career. Knowledge of the larger university structure and how it works is useful. In our own effort, Dandekar's experience as a central administrator was invaluable in knowing how to leverage the resources at hand to get additional support.

It would also be useful, perhaps, to think of a typology of conferences based on the issues and the purpose of the conference. Such a typology might be designed to assist potential conference planners in identifying what kind of gathering would best suit their goal and identify some foreseeable constraints. A lecture series by invited experts might be a way of widening the audience for an area of inquiry, versus a conference with invited speakers which might be a way of pushing forward thinking in an emerging field. An open conference, such as this one, might be the best type in the very early stages of an area of interest, when it is necessary for academics to examine the terrain with policy makers, practitioners, and activists in a collective effort, and then push forward research and policy agendas. Each of these comes with its own set of logistical burdens.

\section{Pedagogical Insights}

Many of the students said that they would count this as one of the highlights of their time at University of Michigan and, both in process and substance, one of their most important learning experiences. The fact that we had in attendance policy makers such as the head of India's Housing and Urban Development Corporation and a member of the Bangladesh Planning Commission in addition to academics, practitioners, and activists was a 
good experience for students. While east coast and west coast universities may have a constant flow of policy makers and practitioners from the international development arena, students at University of Michigan have traditionally had less exposure to that world. Some of the students have already pursued aspects of the conference in other courses, and a majority of those we spoke to volunteered that this conference experience has sensitized them to the issues it raised and has led to aspects of shelter, women, and development becoming recurring elements in their work.

Substantively, this conference was a way for many of us to clarify ideas about shelter, women, and development and the connections between them. In an early communication with Dandekar, Peter Marcuse ${ }^{8}$ addressed the problem of specialism (a topic he has addressed at length in other venues [Marcuse 1989]), the extent to which housing problems of a subgroup of the population should be addressed independently of housing problems in general. We were unable to answer him decisively at that point. Thinking about and understanding why women might have a special need for shelter was an important part of the questions we were asking and for which we now have some answers. We feel that this clarity is an important step in developing thinking, especially in an emerging field. The response that our call for papers elicited from many different parts of the world, particularly from activists and practitioners, indicated that people were talking about realities as they existed in their part of the world-problems that women were having with access to shelter and the immediate need to address those problems-in theory, in policy, and in practice. For us, this confirmed what we believed to be true. We were not creating a topic simply because it was intellectually exciting but were providing a much needed forum for people already working in the area in different capacities and in different contexts to talk to each other. The conference helped legitimize, codify, and bring attention to an important but neglected field of inquiry.

For reasons discussed earlier (the newness of the ideas, broad-based participation including students, access to larger infrastructure) it seems to us that such a conference is likely to be held, if at all, only in a university. The conference was important because this was the only kind of forum that could have brought together the range of participants that it did. For example, work from Africa, India, or Mexico, which would normally be presented independently in area-studies literature, had a joint framework. We would have benefited greatly from presentations from the Second World, where the relative position of women and political realities form an entirely different context from those presented at the conference.

For graduate students it was an interesting experience, even if for some the topics were of peripheral rather than direct interest. It was particularly useful to graduate students who were in the process of exploring the terrain and staking out an area of interest. For doctoral students who were in the research and writing phase of their dissertations, it was often difficult to make the commitment, even if they were interested in aspects of the conference. For all students it was a chance to get a closer view of the inner workings of academic life.

We believe that this conference exemplified one way to globalize planning education. Dandekar is a member of the ACSP Commission on Global Approaches to Planning Education. One of the task force's primary efforts has been to suggest ways that planning curricula can reflect global needs and concerns, not just local ones. Another effort has been to suggest ways to connect between theory and practice, given planning education's inherently practiceorientation in this country. Perhaps experiments in teaching that went into the execution of this conference-the melding of theoretical work with practice, and making things happen-can offer other examples, beyond the workshop/studio model, on how we might deal with these concerns. The range of issues framed by the themes of the conference, seen from the perspectives of different countries and colored by whether one was an academician or policy maker (theory), practitioner or activist (praxis), made for an interesting juxtaposition of ideas and a valuable teaching tool—one for which few substitutes involving less pain and effort are available.

Authors' Note: The authors are indebted to comments from Prof. Seymour Mandelbaum and two anonymous reviewers who helped to bring focus and sharpen the central theme of this paper. We appreciate their help to step back and take a broader look at our experience.

\section{- Notes}

1. Albert O. Hirschman $(1967,12)$ quite accurately points out that there is a snowball effect in the amount of vesting that a host country put into deveiopment projects. As time elapses and commitments increase, the complexity of the task unfolds in all its details.

2. The terms First and Third Worlds have been used in this paper and in the conference although they are ill-defined and, furthermore, are considered western-biased, and therefore objectionable on ideological and/or philosophical grounds. Given the fact that a three-world classification of countries during the Cold War era of First-World Washington, Second-World Moscow confrontations and the emergence of a Third World attempting to find a alternative path for humanity is no longer applicable, the terms First and Third Worlds have been used here as indicating an economic and material reality of nation states, of aggregate affluence versus poverty. The terms offer a simple and imagable shorthand to very complicated and differentiated economic and social realities throughout the world.

3. The book on the exhibit will provide, in visual form, the threedimensional aspects of this issue and the innovation and experimentation that has resulted from practitioner efforts to find solutions.

4. Dandekar, in her position as Associate Vice President for Research at the University of Michigan (1987-1990), was responsible for organizing several campus-wide conferences and seminars. These were much easier to undertake with the resources of the central administrative apparatus to draw on. However, the substantive and conceptual underpinnings of these gatherings were of a very different kind than may be generated by initiatives of faculty/ students/researchers. 
5. This was manifested when Dandekar, in her role as Associate Vice President for Research, was involved in 1989-90 in a campus-wide initiative to reveal the role of state and local initiatives in the research endeavors of the faculty. The report of that conference, which was an initiative of the faculty senate and which drew in central administrative offices of the Provost and Vice Presidents for Research and Governmental Relations, is yet to be released by central administration for campus-wide dissemination.

6. Moser and Peake (1987) provided the greatest contribution to a theoretical framework, but this was based on cases only from the Third World, primarily set in Latin America.

7. The exhibit was documented and received recognition elsewhere, including prestigious awards from Interiors (January 1993) and the Association of the Collegiate Schools of Architecture. A monograph documenting the exhibit is currently in progress.

8. In a personal letter to Dandekar, Peter Marcuse talked about the issues the conference intended to address and raised questions about why such an attention to women's special housing needs was warranted. For an elaboration of his views, see Marcuse (1989, 113 128).

\section{- ReferenCes}

Dandekar, H. C. 1986. Men to Bombay, Women at Home: Urban Influence on Sugao Village, Deccan Maharashtra, India 1942-1982. Ann Arbor: CSSEAS, University of Michigan.

Dandekar, H. C., ed. 1993a. Shelter, Women and Development: First and Third World Perspectives. Ann Arbor, Michigan: George Wahr Publishing.

Dandekar, H. C. 1993b. Women's views of shelter-related services and infrastructure in Charkop, Bombay, and Mogappair, Madras. In Shelter, Women and Development: First and Third World Perspectives, ed. H. C. Dandekar. Ann Arbor, Michigan: George Wahr Publishing.

Dandekar, H. C. In press. Women and housing: The understated relationship to development. Economic and Political Weekly.

Hirschman, A. O. 1967. Development Projects Observed. Washington, D.C. Brookings Institution.

Lindblom, C. E. 1965. The Intelligence of Democracy: Decision Making Through Mutual Adjustment. New York: The Free Press.

Marcuse, P. 1989. The pitfalls of specialism: Special groups and the general problem of housing. In Housing Issues of the 1990's, eds. S. Rosenberry and C. Hartman. New York: Praeger.

Moser, C. O. N., and L. Peake, eds. 1987. Women, Human Settlements and Housing. London: Tavistock.

Schön, D. A. 1971. Beyond the Stable State. New York, London: W. W. Norton. 